This document is confidential and is proprietary to the American Chemical Society and its authors. Do not copy or disclose without written permission. If you have received this item in error, notify the sender and delete all copies.

\title{
Impact of Quadrupolar Electrostatics on Atoms Adjacent to the Sigma-Hole in Condensed-Phase Simulations
}

\begin{tabular}{|r|l|}
\hline Journal: & Journal of Chemical Theory and Computation \\
\hline Manuscript ID & ct-2016-00202d.R1 \\
\hline Manuscript Type: & Article \\
\hline Complete List of Authors: & $\begin{array}{l}\text { El Hage, Krystel; University of Basel, Department of Chemistry } \\
\text { Bereau, Tristan; Max Planck Institute for Polymer Research, } \\
\text { Jakobsen, Sofie; Aarhus University, Department of Chemistry } \\
\text { Meuwly, Markus; University, Chemistry }\end{array}$ \\
\hline
\end{tabular}

\section{SCHOLARONE $^{\text {me }}$ \\ Manuscripts}




\title{
Impact of Quadrupolar Electrostatics on Atoms Adjacent to the Sigma-Hole in Condensed-Phase
}

\section{Simulations}

\author{
Krystel El Hage, ${ }^{\dagger}$ Tristan Bereau, ${ }^{\ddagger}$ Sofie Jakobsen, ${ }^{\dagger, \uparrow}$ and Markus Meuwly ${ }^{* \dagger}$ \\ $\dagger$ Department of Chemistry, University of Basel, Klingelbergstrasse 80, 4056 Basel, \\ Switzerland \\ $\ddagger$ Max Planck Institute for Polymer Research, Ackermannweg 10, 55128 Mainz, Germany \\ IDepartment of Chemistry, Aarhus University, Langelandsgade 140, 8000 Aarhus C, \\ Denmark \\ E-mail: m.meuwly@unibas.ch
}

\begin{abstract}
Halogenation is one of the cases for which advanced molecular simulation methods are mandatory for quantitative and predictive studies. The present work provides a systematic investigation of the importance of higher-order multipoles on specific sites of halobenzenes, other than the halogen, for static and dynamic properties in condensedphase simulations. For that purpose, solute-solvent interactions using point-charge (PC), multipole (MTP) and hybrid point-charge/multipole (HYB) electrostatic models are analyzed in regions of halogen bonding and extended to regions of $\pi$ orbitals of phenyl carbons. Using molecular dynamics simulations and quantum chemical methods it is found that the sigma-hole does not only affect the halogen and the carbon bound to it but its effect extends to the carbons adjacent to the CX bond. This effect increases with the magnitude of the positive potential of the sigma-hole. With the MTP and


HYB3 models all hydration free energies of the $\mathrm{PhX}$ compounds are reproduced within $0.1 \mathrm{kcal} / \mathrm{mol}$. Analysis of pair distribution functions and hydration free energies of halogenated benzenes provides a microscopic explanation why "point-charge"-based representations with off site charges fail in reproducing thermodynamic properties of the sigma-hole. Application of the hybrid models to study protein-ligand binding demonstrates both, their accuracy and computational efficiency. 


\section{Introduction}

Over the past 10-15 years, halogenation has emerged as one of the important chemical modifications pursued in medicinal, ${ }^{1-3}$ materials and supramolecular chemistry ${ }^{4,5}$. Halogenbonding was sought-after in rational drug design due to the directionality of the interaction, its tunability and its hydrophobicity. ${ }^{2,6-11}$ It has enabled in several instances the successful design of ligands with improved binding affinities towards their targets. ${ }^{12,13}$ Nowadays, halogenated compounds, containing F, Cl, Br and I constitute $20 \%$ of all pharmaceutical small molecule drugs used in medicinal chemistry, ${ }^{14}$ several of which are halogenated phenyl rings. Examples include antiviral drugs (HIV-1 integrase inhibitors), ${ }^{15,16}$ kinase inhibitors (GSK-3 (glycogen synthase kinase-3)) ${ }^{17}$ and psychoactive reactional drugs. ${ }^{18}$

Covalently bonded halogen atoms exhibit a sigma-hole, which sometimes results in a positive electrostatic potential along the CX bond (see figure in Table 1) that can interact with negatively charged sites on other molecules, and a negative electrostatic potential on the flanks. The positive sigma-hole character is enhanced along the $\mathrm{F}<\mathrm{Cl}<\mathrm{Br}<\mathrm{I}$ series, upon going from the lighter to the heavier halogen. ${ }^{19-23}$ Due to the anisotropy of the charge distribution, an understanding of the underlying electronic properties is critical for developing improved empirical force fields to capture the sigma-hole in order to accurately compute ligand binding free energies. This will provide valid predictions when optimizing ligands for their target. For a target protein and a series of inhibitors it is possible to determine accurate relative affinities $\Delta G$ from computations. ${ }^{24}$ However, the free energy differences $\Delta \Delta G$ may be smaller than the relative errors in the calculations and result in false positive and false negative predictions. An example for the functional relevance of differential stabilization energies of $\sim 1 \mathrm{kcal} / \mathrm{mol}$ is afforded by the experimental observation that a difference of 0.7 $\mathrm{kcal} / \mathrm{mol}$ in the $\Delta G \mathrm{~s}$ between two candidate therapeutic proteins can markedly increase the thermodynamic stability and physiological availability of one analog relative to the other. ${ }^{25}$ It is therefore critical to reduce the margins of uncertainty through the use of refined molec- 
ular electrostatic potentials that capture the positive lobe of the sigma hole and enables a significant exploration of phase-space which is directly linked to correctly accounting for entropic contributions.

Hydration free energies constitute an experimentally accessible target quantity which is ideally suited to validate force fields. Simple point-charge (PC) descriptions of the electrostatic potentials, which assign a partial charge to each atom in the system, do not accurately reproduce the hydration free energies $\Delta G_{\text {hyd }}$ of halogenated compounds ${ }^{26-28}$ as they fail to reproduce the positive lobe of the sigma-hole. ${ }^{7,29}$ Two point charges (i.e., on $\mathrm{C}$ and $\mathrm{X}$ ) cannot describe the strong electrostatic variation across the $\mathrm{C}-\mathrm{X}$ bond. In order to account for this effect, a partial positive charge can be added in the region of the sigma-hole along the $\mathrm{C}-\mathrm{X}$ bond. ${ }^{27,30-32}$ This is akin to including additional point charges for modeling higher order multipoles as has been done for carbon monoxide. ${ }^{33-35}$ However, the hydration free energies from such improved "PC-based" models, (e.g. the OPLS-AAx force field with an extra PC on the halogen) still showed significant discrepancies for $\mathrm{PhCl}$ and $\mathrm{PhBr}$ (between 0.5 and $1 \mathrm{kcal} / \mathrm{mol}$ ), while they obtained satisfactory results for $\mathrm{PhI}{ }^{27}$ The reasons for this remained unclear. Using a PC force field, that does not account for the positive cone of the sigma-hole, leads to low $\Delta G_{\text {hyd }}$ that significantly differ from experimental values by $0.5 \pm 0.01$ and 0.91 $\pm 0.04 \mathrm{kcal} / \mathrm{mol}$ for $\mathrm{Cl}$ and $\mathrm{Br}$, respectively. ${ }^{26}$ Simulations with the OPLS-AAx force field with an extra PC on the halogen, reproducing the sigma-hole feature, resulted in $\Delta G_{\text {hyd }}$ that are very close to those from a pure PC model and differ from experimental values by 0.37 and $0.25( \pm 0.05 \mathrm{kcal} / \mathrm{mol})$ for $\mathrm{Cl}$ and $\mathrm{Br}$, respectively. ${ }^{27}$ Contrary to that, using higher-order multipole (MTP) expansions of the electrostatic potential in molecular simulations instead of the more customary point charges (PC) have provided more accurate solvation free energies $\Delta G_{\text {hyd }}{ }^{26}$ The improved description of the intermolecular dynamics when using MTP force fields in classical molecular dynamics (MD) simulations of condensed-phase systems was previously validated in combined experimental-computational studies. They included the 
2-dimensional infrared (2d-IR) spectroscopy of small molecules in water like cyanide $\mathrm{CN}^{-}, 36$ $\mathrm{N}$-methylacetamide $\mathrm{NMA}^{37}$ and fluoro-acetonitrile $\mathrm{F}-\mathrm{ACN},{ }^{38}$ where differences in the first solvation shell in MTP compared to PC simulations were validated by comparing correlation and decay times of solute-solvent interactions from experiment. Other important efforts to better account for the anisotropy of the charge distribution of halogens included polarizable multipole force fields like SIBFA ${ }^{39-41}$ and AMOEBA $^{42}$ and the polarizable ellipsoid force field for halogen bonds PEff. ${ }^{43}$

Because computational investigations of solvation phenomena require extensive sampling (repeated simulations on the multi-nanosecond time scale), mixed quantum mechanics (QM) molecular mechanics (MM) QM/MM simulations at the DFT-level with sufficiently large basis sets are usually not possible. It is therefore critical to have suitable quantitative and validated force fields. For the present case this amounts to correctly capturing the positive lobe of the sigma-hole and effects extending over regions adjacent to the modification site. Here, the impact of the description of the sigma-hole and the neighboring atoms on thermodynamic observables was determined. The above mentioned PC and MTP electrostatic models provide means to unambiguously isolate the role of each chemical group in computing hydration free energies or radial distribution functions. Starting from a simple PC description, an increasing number of atoms with an improved distributed multipole description was systematically included in mixed PC/MTP models as indicated in Table 1 . This leads to hybrid PC/MTP models 1, 2 and 3 (HYB1, HYB2, HYB3), based on previously validated PCs, MTPs and LJ parameters were used. ${ }^{26} \mathrm{HYB} 1$ has MTPs on the halogen X and $\mathrm{C}_{\alpha}$ bound to it and PCs on the rest of the atoms, HYB2 with additional MTPs on all atoms except for the adjacent carbons $\mathrm{C}_{\beta}$ and HYB3 has MTPs on the CX group and the two $\mathrm{C}_{\beta}$. Full multipole models provide a near-redundant set of parameters, meaning that some of the multipoles do not improve the accuracy of the electrostatic energy. ${ }^{44}$ The current work quantifies the performance of three such hybrid models which are particularly relevant 
since they can provide similar accuracy compared to the full MTP model for the observables considered here (hydration free energy) at reduced computational cost. The approach chosen here also allows to analyze and understand the importance of correctly capturing the dynamics around chemically interesting sites (e.g. halogens) and the degree to which MTP parametrizations are transferable from one chemical system to another one.

\section{Computational Methods}

\subsection{Molecular Dynamics Simulations}

All MD simulations were carried out with $\mathrm{CHARMM}^{45}$ together with provisions for static atomic multipolar simulations. ${ }^{26}$ The models considered include a conventional point-charge (PC), a multipole (MTP) and hybrid (PC/MTP) models. The hybrid models are a mixed PC/MTP parametrization containing atoms treated with the PC parameters and others with MTP parameters, see Figure in Table 1. Charges, multipoles and LJ parameters were those from previous work $^{26}$ where the PC/MTP parameters were fit to the ESP and the vdW parameters were fit to experimental thermodynamic properties like density, heat of vaporization and hydration free energy (see SI.I for more details). Polarization effects are included implicitly in the Coulomb and LJ parameters. ${ }^{46,47}$ In addition, mixed quantum mechanics/molecular mechanics (QM/MM) simulations employing the density functional tight binding (DFTB2) method were performed using the van der Waals radii of the corresponding atom types from a PC treatment. ${ }^{48,49}$ In the context of the present work, DFTB2 provides fluctuating point charges but may not faithfully capture the anisotropy of the electrostatic interactions and hence serves as a model between PC (static) and MTP (anisotropic). In all simulations, the TIP3P model was used for water. ${ }^{50}$ For PC-PC interactions, PME was used with grid spacing of $1 \AA$, a relative tolerance of $10^{-6}$ and a cutoff of $12 \AA$, together with a $10 \AA$ switching for the Lennard-Jones (LJ) interactions. For higher MTP interactions a power-law dependent switching was employed. ${ }^{26}$

\section{ACS Paragon Plus Environment}


Each system was first energy minimized using steepest descent, then heated from 0 to $298 \mathrm{~K}$ at constant volume for $40 \mathrm{ps}$, and equilibrated in the NPT ensemble at $p=1$ atm for $40 \mathrm{ps}$ using a Langevin damping coefficient of $\gamma_{p}=20 \mathrm{ps}^{-1}$ on the piston. Bonds involving hydrogens were constrained with SHAKE. ${ }^{51}$ The Hoover heat-bath method provided temperature and pressure coupling, using masses as reported previously. ${ }^{26}$

Thermodynamic Integration: Hydration free energies were computed using thermodynamic integration (TI). Applying a control parameter $\lambda$, TI switches between the initial $(\lambda=0$, state $\mathrm{A})$ and the final $(\lambda=1$, state $\mathrm{B})$ state by gradually altering all nonbonded interactions. Working in the slow-growth regime, the free energy is

$$
\Delta G_{\mathrm{A} \rightarrow \mathrm{B}}=\int_{0}^{1} \mathrm{~d} \lambda\left\langle\frac{\partial \mathcal{H}}{\partial \lambda}\right\rangle_{\lambda} \approx \sum_{i}\left(\lambda_{i+1}-\lambda_{i}\right)\left\langle\frac{\partial \mathcal{H}}{\partial \lambda}\right\rangle_{\lambda_{m}}
$$

where $A \rightarrow B$ refers to the transformation between states $\mathrm{A}$ and $\mathrm{B}$, the canonical average $\langle\cdot\rangle_{\lambda}$ is performed over the phase space generated by $\mathcal{H}(\lambda)$, and $\lambda_{m}=\left(\lambda_{i}+\lambda_{i+1}\right) / 2$. Derivatives of the Lennard-Jones and PC electrostatic energies were obtained from the PERT module, using soft-core potentials for the LJ interactions. ${ }^{52,53}$ The change in free energy due to MTP electrostatics with coupling $\lambda_{m}$ was computed as described in Ref. ${ }^{26}$ In these simulations, first the LJ interactions were fully grown in the presence of soft-core potentials. Next, the electrostatic interactions were turned on, in order to avoid the need for soft-core electrostatic potentials.

Using a thermodynamic cycle, ${ }^{54}$ the hydration free energy $\Delta G_{\text {hyd }}$ is calculated as the difference of the free energy of insertion of the compound between water $\Delta G_{\text {sol }}$ and vacuum $\Delta G_{\mathrm{vac}}, \Delta G_{\mathrm{hyd}}=\Delta G_{\mathrm{sol}}-\Delta G_{\mathrm{vac}}$. 


\subsection{Quantum Chemical Calculations}

The electron distribution around the target molecules was also analyzed from electronic structure calculations using Gaussian 09. ${ }^{55}$ They were carried out for the optimized structure using the dispersion-corrected B97-D functional ${ }^{56}$ and the aug-cc-pVTZ ${ }^{57,58}$ basis set, except for Iodine for which the pseudo-potential containing basis set, aug-cc-pVTZ-PP 59 The Electron Localization Function (ELF) quantifies the amount of Pauli repulsion based on the conditional probability of finding an electron close to a reference electron of the same spin. ${ }^{60,61}$ The volumes delimited by an isosurface of the ELF function defines the localization domains. ELF basins correspond to minimal Pauli repulsive areas around a local maximum, and they are divided into core basins $C$ (containing the nucleus) and valence basins $V$ (bonds and lone pairs). The ELF analysis was done with the TopMod program. ${ }^{62}$ Furthermore, the molecular electrostatic potential (MEP) for the four halobenzenes $(\mathrm{X}=\mathrm{F}, \mathrm{Cl}, \mathrm{Br}, \mathrm{I})$ used the electron density from the same Gaussian calculations employed for the ELF analysis and they were mapped at the $10^{-3} e a_{0}^{-3}$ isodensity surface, using Gaussview5. ${ }^{63}$ In all calculations the optimized structure of the halogenated benzenes was used.

\section{Results and Discussion}

\subsection{Hydration free energies}

Table 1 summarizes the experimental and calculated hydration free energies $\Delta G_{\text {hyd }}$ using the different electrostatic models, with typical errors of $\pm 0.05 \mathrm{kcal} / \mathrm{mol}$, consistent with previous work. ${ }^{26,27}$ It was shown that for benzene, both PC and MTP models are equally able to reproduce the experimental hydration free energy $\Delta G_{\text {hyd }}{ }^{26}$ The PC model is clearly deficient for all halogenated phenyls. The substitution of PCs with MTP on the CX group (HYB1) slightly improves $\Delta G_{\mathrm{hyd}}$, bringing them closer by 0.2 to $0.3 \mathrm{kcal} / \mathrm{mol}$ to the full MTP model and experimental results. Nevertheless, the presence of the sigma-hole electrostatics on the 
halogen and the $\mathrm{C}_{\alpha}$ carbon is still not satisfactorily accounted for. HYB2 (MTPs on all atoms except for the adjacent carbons $\mathrm{C}_{\beta}$ ) does not improve $\Delta G_{\text {hyd }}$ compared to HYB1. Hence, the three systems respond differently to such mixed models which emphasizes that carbon atoms adjacent to the halogen are important. In contrast, when including the carbon atoms two bonds away from the modification site into the MTP treatment, $\Delta G_{h y d}$ falls within $10 \%$ (i.e. $0.1 \mathrm{kcal} / \mathrm{mol}$ or less) of the full MTP results. Finally, a single-site MTP on $\mathrm{Br}$ in $\mathrm{PhBr}$ with optimized vdW parameters was not able to reproduce the thermodynamic properties corroborating that the adjacent carbon atoms need to be treated at a higher than the PC level. The resulting $\Delta G_{\text {hyd }}$ was $-0.81 \mathrm{kcal} / \mathrm{mol}$, placing it between the $\mathrm{PC}(-0.62$ $\mathrm{kcal} / \mathrm{mol})$ and the HYB1 $(-0.94 \mathrm{kcal} / \mathrm{mol})$ models.

Table 1: The different electrostatic models: PC (far left), MTP (far right) and the hybrid PC/MTP models HYB1, HYB2 and HYB3; and comparison of hydration free energies $\Delta G_{\text {hyd }}$ between experimental results ${ }^{64}$ and the different electrostatic models for $\mathrm{PhX}(\mathrm{X}=\mathrm{F}, \mathrm{Cl}, \mathrm{Br}$ and I).

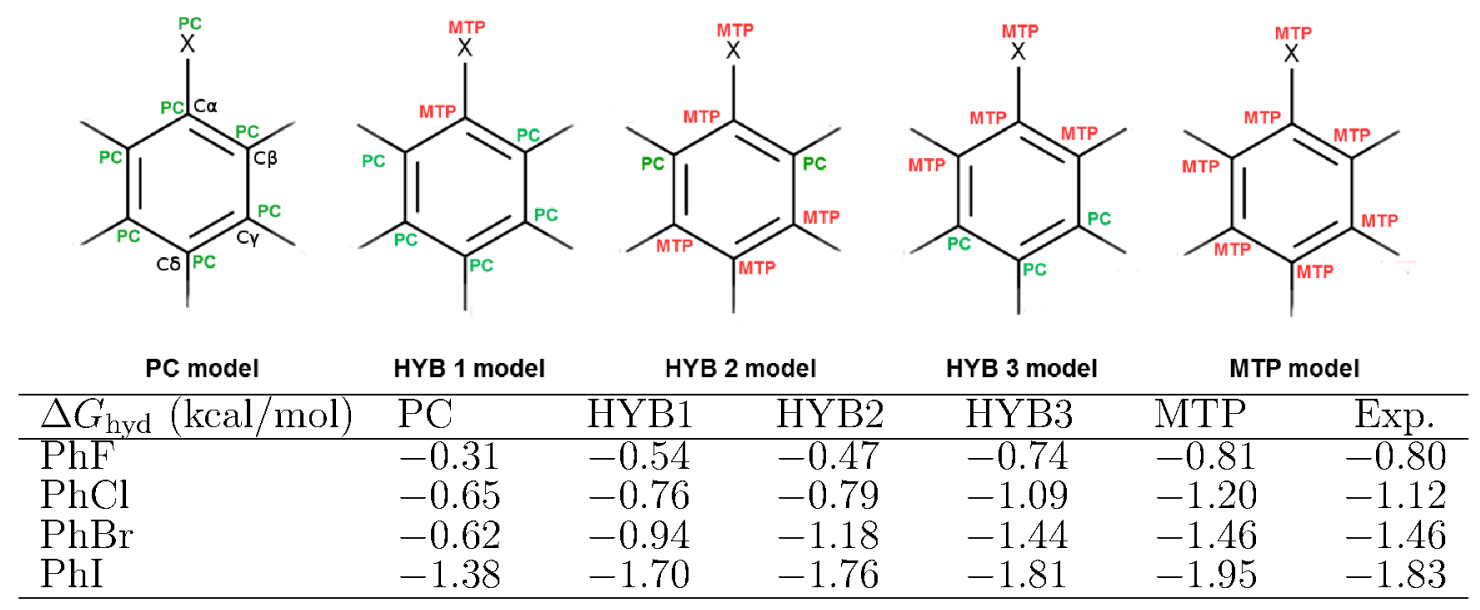




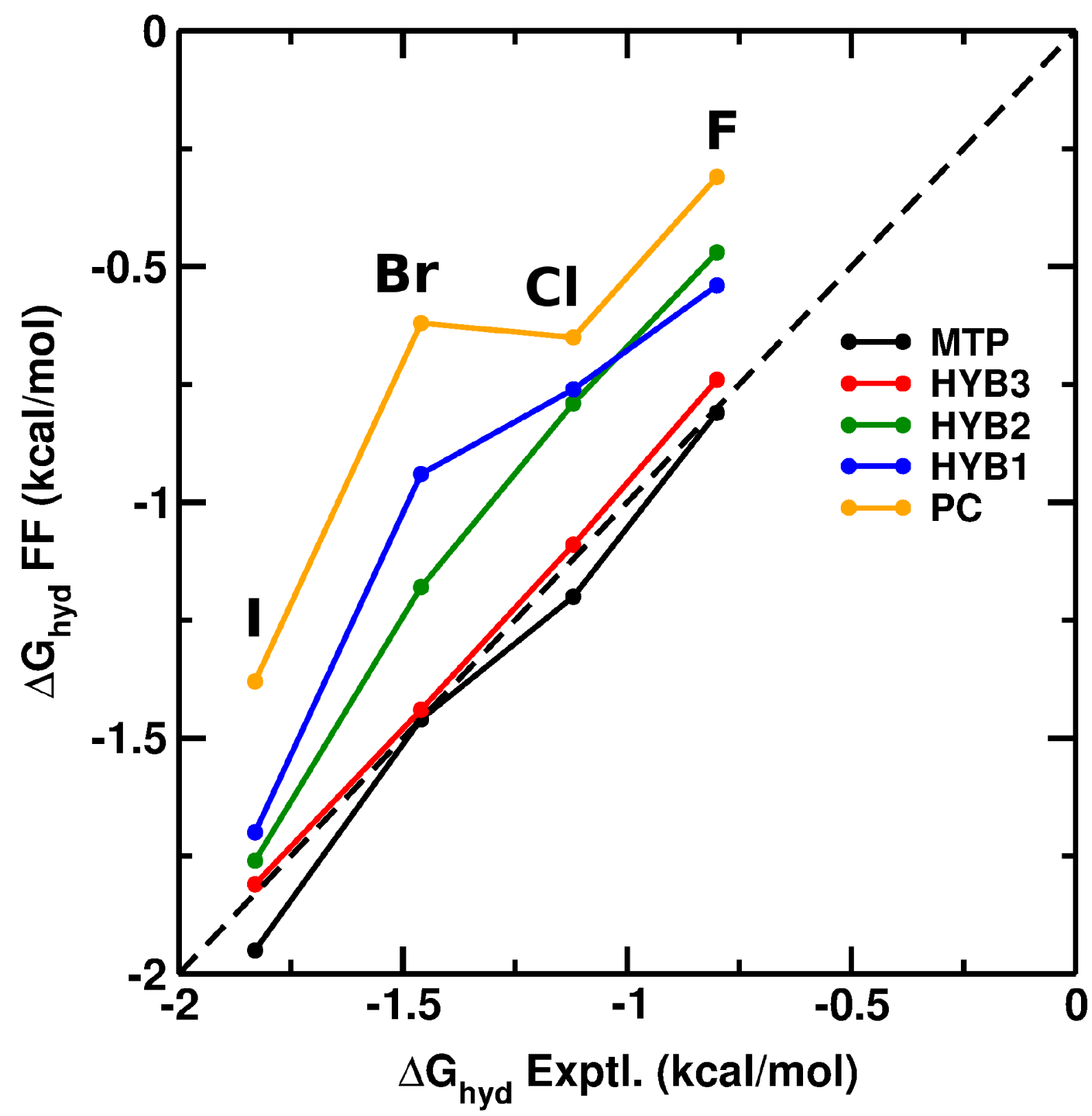

Figure 1: Correlation between the experimental and calculated hydration free energies for $\mathrm{F}, \mathrm{Cl}, \mathrm{Br}$ and I depending on the electrostatic model employed.

Therefore, in order to accurately describe the solvation free energy it is necessary to not only use MTPs for the halogen to capture the sigma-hole, but also to employ MTPs for the carbon atoms next to it, specifically those bonded to the $\mathrm{CX}$ group $\left(\mathrm{C}_{\beta}\right)$. While the shortcomings of PC models stem from evident limitations for two point charges to generate anisotropic electrostatic potentials, the presence of many atoms around the $\mathrm{C}_{\alpha}$ and $\mathrm{C}_{\beta}$ 


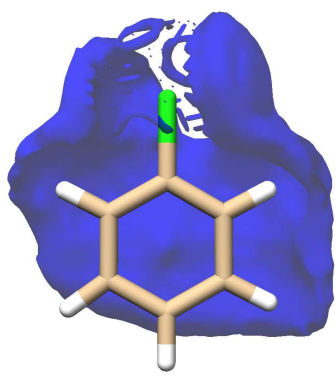

(a)

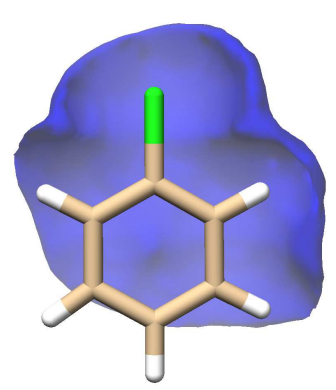

(b)

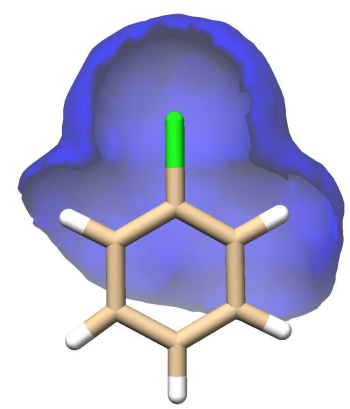

(c)

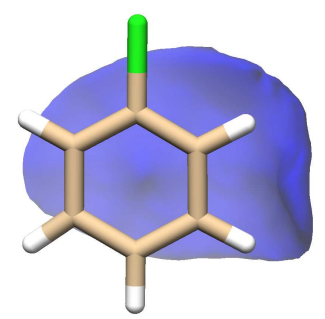

(d)

Figure 2: Isosurfaces of the difference between MTP and (a) PC and (b) HYB1 and (c) HYB2 and (d) HYB3 ESPs of PhCl. Blue regions denote the error propagation around atomic sites. The root-mean squared error in the first interaction belt of $\mathrm{PC}, \mathrm{HYB}(1,2,3)$ and MTP ESPs with respect to the ab initio potential are $0.92,0.67,0.53,0.47$ and 0.32 $\mathrm{kcal} / \mathrm{mol}$, respectively.

The difference between the full MTP density and that generated by the PC and hybrid models is shown in Figure 2. With MTPs on $\mathrm{X}$ and $\mathrm{C}_{\alpha}$ in HYB1 (Figure 2b) the error around these sites decreases compared to the PC model (Figure 2a)). However an error still persists around the CX bond. The addition of MTPs on the $\mathrm{C}_{\beta}$ (HYB3) shows a large improvement in reproducing the full MTP model, and removes the error around the CX bond (Figure 2d). In contrast, the model lacking MTPs on $\beta$ carbons (HYB2 model, Figure 2c) alters the 
overall electrostatics around the halogen even though the latter has MTPs. This also shows that the lack of an explicit out-of-plane contribution to the $\pi$ orbitals around the $\beta$ carbons has a significant impact on the overall electrostatics of the CX group and $\mathrm{C}_{\beta}$ carbons which in part explains the underestimated $\Delta G_{\text {hyd }}$ when replacing multipoles on these atoms by PCs (HYB2) and the accurate reproduction of $\Delta G_{\mathrm{hyd}}$ when placing MTPs on these atoms (HYB3).

As an independent assessment of these observations the electron localization function (ELF) ${ }^{60,61}$ was analyzed for PhF to $\mathrm{PhI}$ and $\mathrm{PhH}$ as reference. The ELF provides chemically intuitive information concerning chemical bonds and lone pairs. Figure 3a reports ELF localization domains along the series $\mathrm{F}<\mathrm{Cl}<\mathrm{Br}<\mathrm{I}$. The $V(\mathrm{C}, \mathrm{C})$ basin reflects the pronounced $\pi$ character of the $\mathrm{C}-\mathrm{C}$ bond. This arrangement along the $z$-axis further characterizes the nature of $\pi$ orbitals by the quadrupolar moment component $Q_{z z}$.

Compared to $\mathrm{PhH}$, where all $V(\mathrm{C}, \mathrm{C})$ basins have the same volume (196.40 $\left.\mathrm{au}^{3}\right)$ and electron population $(2.76 e)$, all halobenzenes $\mathrm{PhX}$ show an increase in the electronic population and a decrease of the corresponding basin volume around the $\mathrm{C}_{\alpha}-\mathrm{C}_{\beta}$ bonds, that leads to an increased electron density. This is also associated with an increase of the basin volume $V(\mathrm{X})$ around the halogen (Figure $3 \mathrm{~b}$ ). Contrary to that, the remaining $\mathrm{C}-\mathrm{C}$ bonds around the cycle are not affected (see SI.II for the detailed analysis). This suggests that electron delocalization around the $\mathrm{C}_{\alpha}-\mathrm{C}_{\beta}$ bonds arises from a modified electronic distribution in the in-plane $s p$ hybrid orbitals of the $\mathrm{C}_{\alpha}$ and $\mathrm{C}_{\beta}$ carbons which leads to modifications of the orthogonal non-bonding $p$-orbitals on $\mathrm{C}_{\beta}$. This density redistribution causes electronic anisotropy around the atoms and should be reflected when mapping the electrostatic potential.

Figure $3 \mathrm{c}$ visualizes the sigma-hole as a positive potential region along the $\mathrm{C}-\mathrm{X}$ bond (green/blue, extended for I) and a negative potential region on the flanks (red, extended for F). For the 
C-atoms, however, no atom-specific effects are found. The electron distribution over the ring shrinks and turns less electronegative in going from F to I (color shifts from red/yellow to yellow). This is why the anisotropy around the $\mathrm{C}_{\alpha}-\mathrm{C}_{\beta}$ atoms induced by the presence of the halogen is generally left unnoticed.

Overall, both thermodynamic and electronic studies are complementary and suggest that the electron distribution around the halogen has a significant impact on the electrostatic anisotropy of the CX group and the adjacent carbons $\mathrm{C}_{\beta}$. Therefore, an accurate description of the solvation free energy requires capturing the electrostatics around the sigma-hole (the presence of the positive cone) and the off-the-plane contributions of neighboring atoms extending up to the $\mathrm{C}_{\beta}$ carbons adjacent to the CX group.

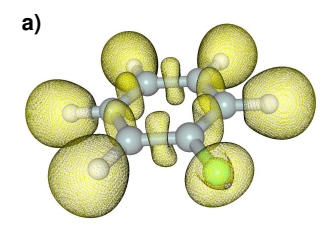

c)

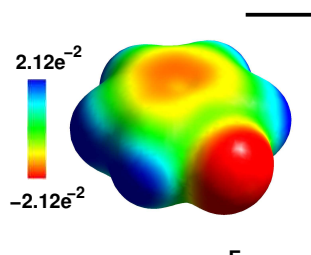

F
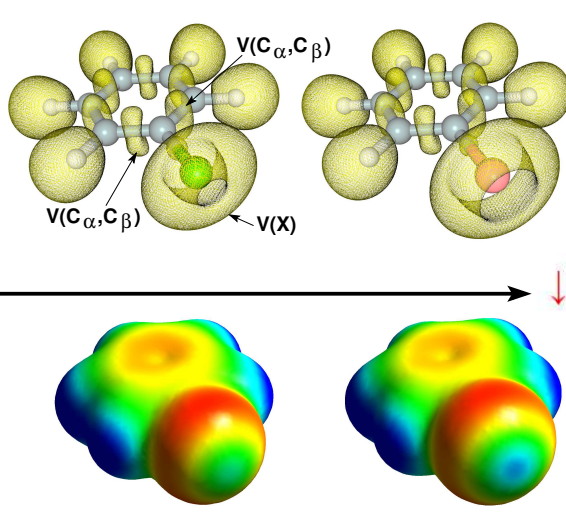

$\mathrm{Cl}$ $\downarrow \delta-$

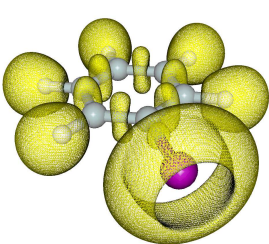

$\uparrow \boldsymbol{\delta}+$

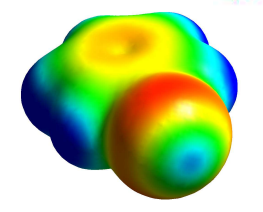

$\mathrm{Br}$ b)

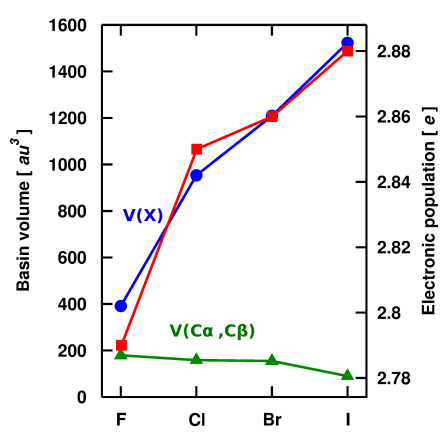

Figure 3: The ELF localization domains and basin populations of halobenzenes along the series $\mathrm{F}<\mathrm{Cl}<\mathrm{Br}<\mathrm{I}$. Panel (a) ELF isosurface $(\eta=0.8)$ for $\mathrm{PhF}$ to $\mathrm{PhI}$ (from left to right). Basins for the lone pairs are denoted $V(\mathrm{X})$, where $\mathrm{X}$ is the halogen; basins related to the atomic bonds are denoted $V(\mathrm{C}, \mathrm{C})$. Panel (b) Basin volume and electronic population for the $\mathrm{PhX}$ molecules. The blue line with circles and the green line with triangles represents the basin volume of $V(\mathrm{X})$ and $V\left(\mathrm{C}_{\alpha}, \mathrm{C}_{\beta}\right)$, respectively; the red line with squares represents the electronic population of $V\left(\mathrm{C}_{\alpha}, \mathrm{C}_{\beta}\right)$. Panel (c) Molecular Electrostatic Potential MEP of $\mathrm{PhX}$, at the $10^{-3} \mathrm{ea}_{0}^{-3}$ isodensity surface. The black arrow indicates the increase in the sigma-hole strength of the halogens $\mathrm{F}<\mathrm{Cl}<\mathrm{Br}<\mathrm{I}$. The red arrow indicates the decrease of the electron rich region $\delta^{-}$on the sides of the $\mathrm{C}-\mathrm{X}$ bond in going from $\mathrm{F}$ to $\mathrm{Cl}$ to $\mathrm{Br}$ to $\mathrm{I}$, and the blue arrow indicates the increase of the electron deficient region $\delta^{+}$along the $\mathrm{C}-\mathrm{X}$ bond from $\mathrm{F}$ to $\mathrm{Cl}$ to $\mathrm{Br}$ to $\mathrm{I}$. 


\subsection{Solvent Structure}

In order to probe the influence of the different electrostatics on the local solvation structure of the probe molecules in water, radial distribution functions $g(r)$ around the halogen and around the $\pi$-system of the benzene ring were analyzed.

First, the radial distribution functions $g(r)$ around the halogen was investigated (Figure 4). For this, the X-water(oxygen) $g_{\mathrm{XO}}$ and X-water(hydrogen) $g_{\mathrm{XH}}$ were determined from 2 ns of NPT simulations with the different charge models PC, MTP and HYB3, and from DFTB2 QM/MM simulations. ${ }^{48,49}$ For PhF, the F-O pair distribution function peaks at $3.2 \AA$ for MTP and HYB3 and the amplitude (reflecting the occupation probability) is similar. However, for the PC model the peak is shifted to shorter distances $(2.5 \AA)$ due to the decreased van der Waals range of fluorine compared to the MTP and the HYB3 model $\left(\sigma_{\mathrm{F}, \mathrm{PC}}=1.1\right.$ $\AA$ vs. $\sigma_{\mathrm{F}, \mathrm{MTP}}=1.7 \AA$ ) and $g_{\mathrm{XO}}<1$. The F-H pair distribution function $g_{\mathrm{FH}}(r)$, exhibits a pronounced first peak at $1.4 \AA$ indicating a hydrogen bond between the fluoride and the water hydrogens. Conversely, for the MTP and HYB3 models, the first peak deforms into a plateau and is shifted to $\approx 2 \AA$. For $\mathrm{Cl}, \mathrm{Br}$ and $\mathrm{I}$, the $g(r)$ resemble each other although the first and second maximum is more pronounced in the case of PC. Simulations with PC, MTP and the HYB3 model yield very similar results whereas DFTB2 leads to somewhat reduced amplitudes for Br and I which is probably related to the parametrization of DFTB2 ${ }^{49}$ which may be improved in DFTB3. ${ }^{65}$ This was reported for several cases due to the presence of a large sigma-hole on $\mathrm{Br}$ and I, but can be enhanced by empirical corrections for halogen bonding. 49 
2
RDF X---O(water)
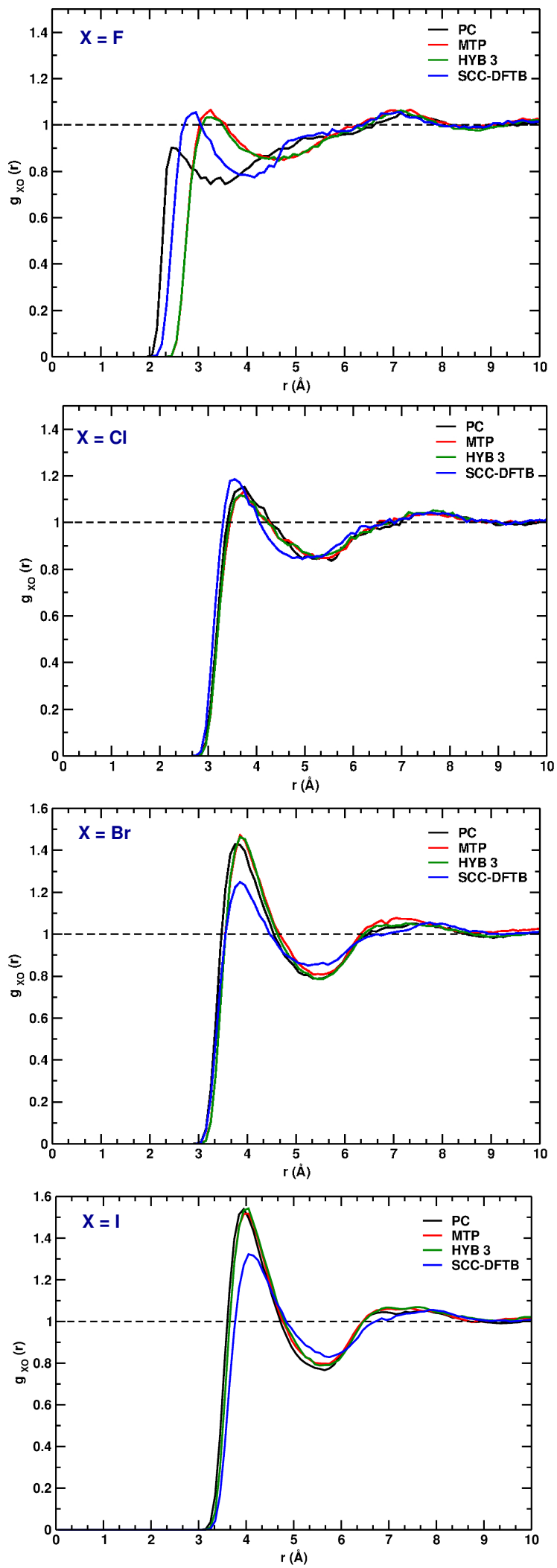

RDF X---H(water)
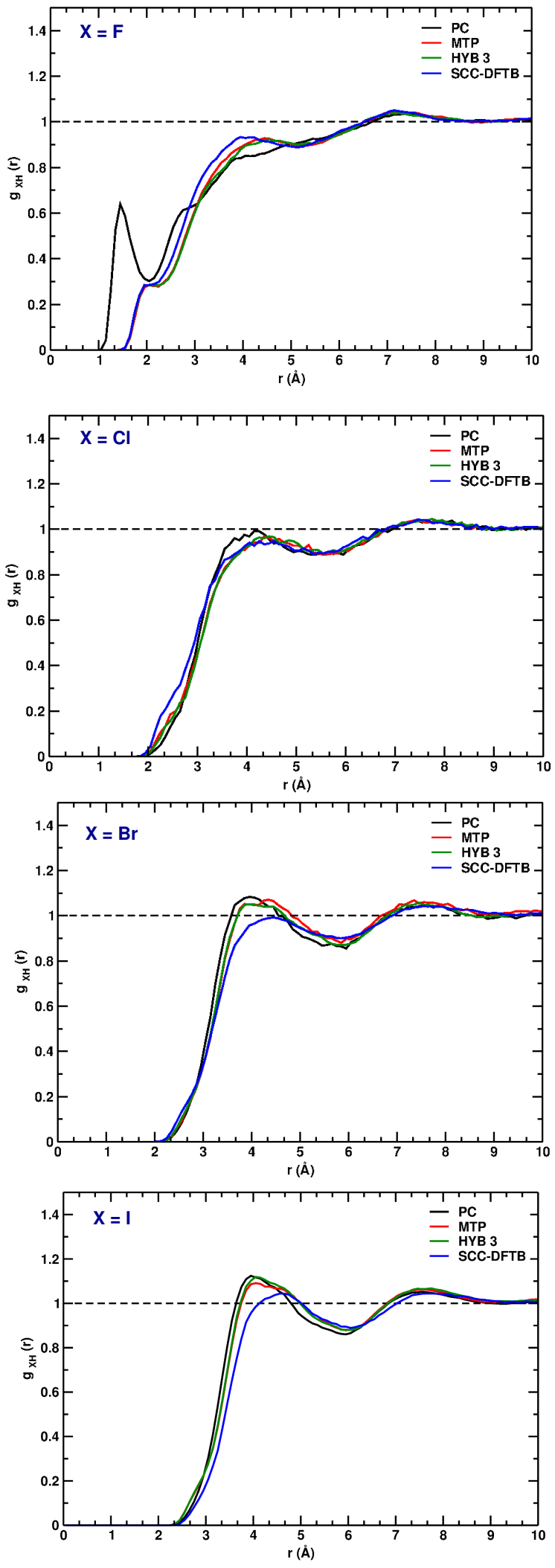

Figure 4: Radial distribution function $g(r)$ for $\mathrm{X}-\mathrm{O}$ (water) (left panels) and for $\mathrm{X}-\mathrm{H}$ (water) (right panels) for four halobenzenes $\mathrm{PhX}, \mathrm{X}=\mathrm{F}, \mathrm{X}=\mathrm{Cl}, \mathrm{X}=\mathrm{Br}$ and $\mathrm{X}=\mathrm{I}$, from top to bottom, for simulations with different electrostatic models. 
Figure 5 shows the calculated $g(r)$ (a) for $\mathrm{X}$-water $(\mathrm{O})$ and (b) for $\mathrm{X}$-water(H) for all halogenated compounds from 2 ns MTP simulations and highlights the role of the electronrich $\left(\delta^{-}\right)$and electron-poor $\left(\delta^{+}\right)$regions of the sigma-hole in $\mathrm{X}$-water interactions. The amplitude of $g_{\mathrm{XO}}(r)$ increases in going from $\mathrm{F}$ to $\mathrm{I}$ which implies a stronger interaction $\left(g(r) \propto \exp (-\beta w(r))\right.$ where $w(r)$ is the potential of mean force) and a larger number of $\mathrm{X}_{-}^{-}$ O interactions through the relationship between $g(r)$ and occupation number (see below). On the contrary, the amplitude of $g_{\mathrm{XH}}(r)$ decreases in going from $\mathrm{F}$ to I which implies a smaller number of $\mathrm{X}-\mathrm{H}$ interactions. The hydrogen-occupation number $N_{H}\left(r_{s}\right)=4 \pi \rho_{H} \int_{0}^{r_{s}} r^{2} g(r) d r$ up to separation $r_{s}$ around the halogen decreases with increasing size of the halogen atom (see Figure $5(\mathrm{~b}))$. Here, $\rho_{\mathrm{H}}$ is the density of hydrogen atoms in the simulation and $g(r)=g_{\mathrm{XH}}(r)$.

An extensive survey of structures in the Cambridge Structural Database together with electronic structure calculations ${ }^{6}$ have characterized the geometry of halogen bonds in small molecules containing F to I. This showed that electronegative atoms (including oxygen and nitrogen) prefer to interact with the $\delta^{+}$of $\mathrm{Cl}, \mathrm{Br}$, and $\mathrm{I}$ (but not $\mathrm{F}$ ) along the $\mathrm{C}-\mathrm{X}$ bond axis. This is confirmed by later studies which show that the electropositive potential along the CX-bond can turn into an H-bond donor through a water bridge. ${ }^{7,66}$ It was also found that for $\mathrm{Cl}, \mathrm{Br}$ and I the unexpectedly large number of short $\mathrm{X}$-water $(\mathrm{O})$ contacts (and for $\mathrm{I}>\mathrm{Br}>\mathrm{Cl})$ is related to a decreased probability to form $\mathrm{X}$-water $(\mathrm{H})$ interactions because the magnitude of the $\delta^{-}$region decreases (see Figure 3 ).

The current observations also support recent static work on the dual feature of the CX bond in halobenzenes in which this doubly-faceted nature was quantified by quantum chemistry (QC) calculations. ${ }^{11,67}$ In other words, the dual character was leveraged in the recognition sites of several target proteins by considering mono- and polysubstituted halobenzenes ${ }^{11}$ and was probed by a bifunctional molecule approaching each of the two regions $\delta^{+}$and $\delta^{-} .{ }^{67}$ In the light of these studies, the present analysis confirms that the increase in amplitude of the 
$g_{\mathrm{XO}}(r)$ peak, in going from $\mathrm{X}=\mathrm{F}$ to $\mathrm{X}=\mathrm{I}$ can be explained by the increase of the volume and strength of the $\delta^{+}$region of the sigma-hole whereas the decrease in amplitude and in occupation of the $g_{\mathrm{XH}}(r)$ (i.e. weakening of the hydrogen bond) is related to the decrease of the volume and strength of the $\delta^{-}$region of the sigma-hole.

The behavior of the H-bonding water network pointing towards the $\pi$-system of the benzene ring was also investigated (Figure SI.2). The RDF plots of the PhX carbons from PC and MTP simulations show a similar behavior of the symmetric carbons with respect to one another, $\left[\mathrm{C}_{\beta 1} ; \mathrm{C}_{\beta 2}\right]$ and $\left[\mathrm{C}_{\gamma 1} ; \mathrm{C}_{\gamma 2}\right]$. The difference between the $g(r)$ plots of both electrostatic models (PC vs. MTP) show that the most affected atoms by the electrostatic representation are the ones closer to the halogen, $\mathrm{C}_{\alpha}$ and $\mathrm{C}_{\beta}$, while $\mathrm{C}_{\delta} \mathrm{C}_{\gamma}$ are less effected (Figure SI.3). These findings correlate with the electronic distribution around these atom sites, obtained by the ELF analysis and provide additional insight why HYB3 accurately describes the solvation free energy.

The superposition of the radial distribution functions $g(r)$ for the water molecules around $\mathrm{C}_{\alpha}$ (Figures SI.4) and $\mathrm{C}_{\beta}$ (Figure SI.5) taken from PC and MTP simulations, show for both water approaches, that the PC representation tends to shift the first peak to lower distances, and the $g(r)$ peak increases when going to larger halogens. This indicates an increased overcoordination of water hydrogen atoms, and translates into an inaccurate representation of the PC model that gets more unrealistic when passing to larger halogens. Figure 6 reports results for $\mathrm{X}=\mathrm{F}$ and $\mathrm{X}=\mathrm{Br}$. The $g(r)$ for the $\mathrm{C}_{\beta}$-water $(\mathrm{H})$ distance displays a shoulder at $\approx 2.5 \AA$ for PC which is less apparent in MTP simulations. This is even more pronounced for the $\mathrm{C}_{\alpha}$ carbon (Figure 6(A) lower panel). Concomitantly, the amplitudes for the $\mathrm{C}_{\alpha}-\mathrm{O}$ and $\mathrm{C}_{\beta}-\mathrm{O}$ radial distribution functions also differ between PC and MTP simulations even though the vdW radii of all carbon atoms in both PC and MTP models are identical $\left(\sigma_{\mathrm{C}, \mathrm{PC} / \mathrm{MTP}}=\right.$ $2.0 \AA)$. Figure $6(\mathrm{~B})$ reports the occupation number difference $\Delta N(r)$ between PC and MTP 
a)

RDF X---O(water)

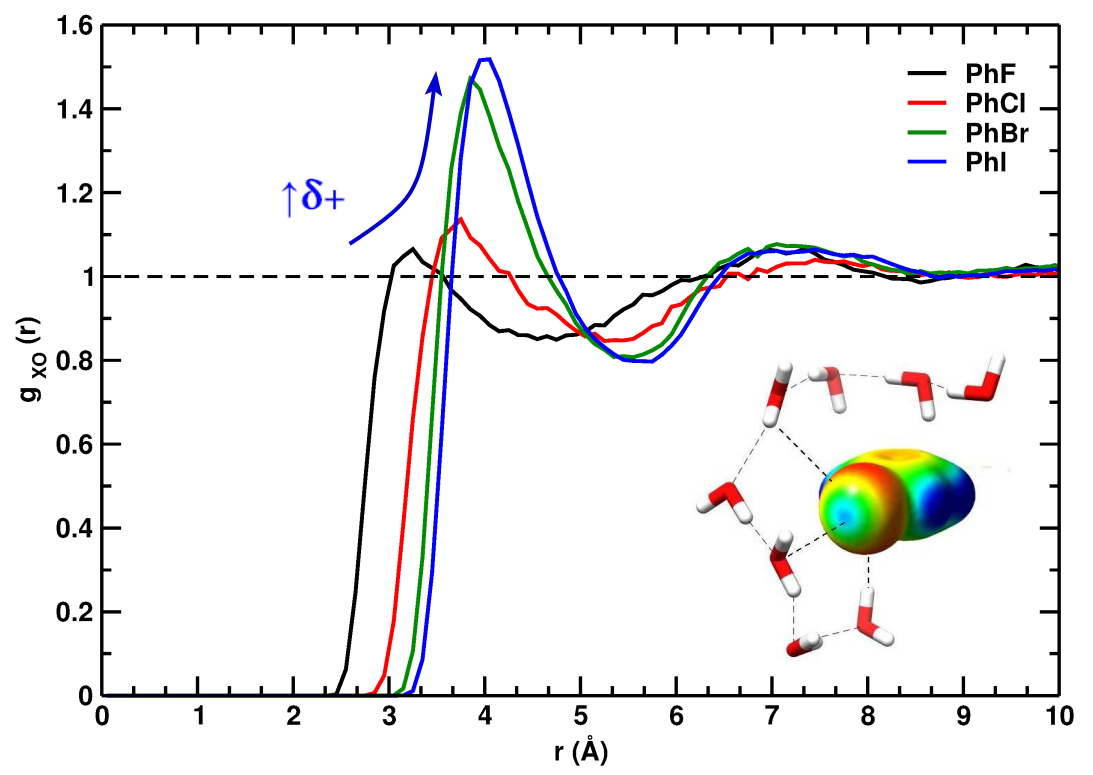

b) RDF X---H(water)

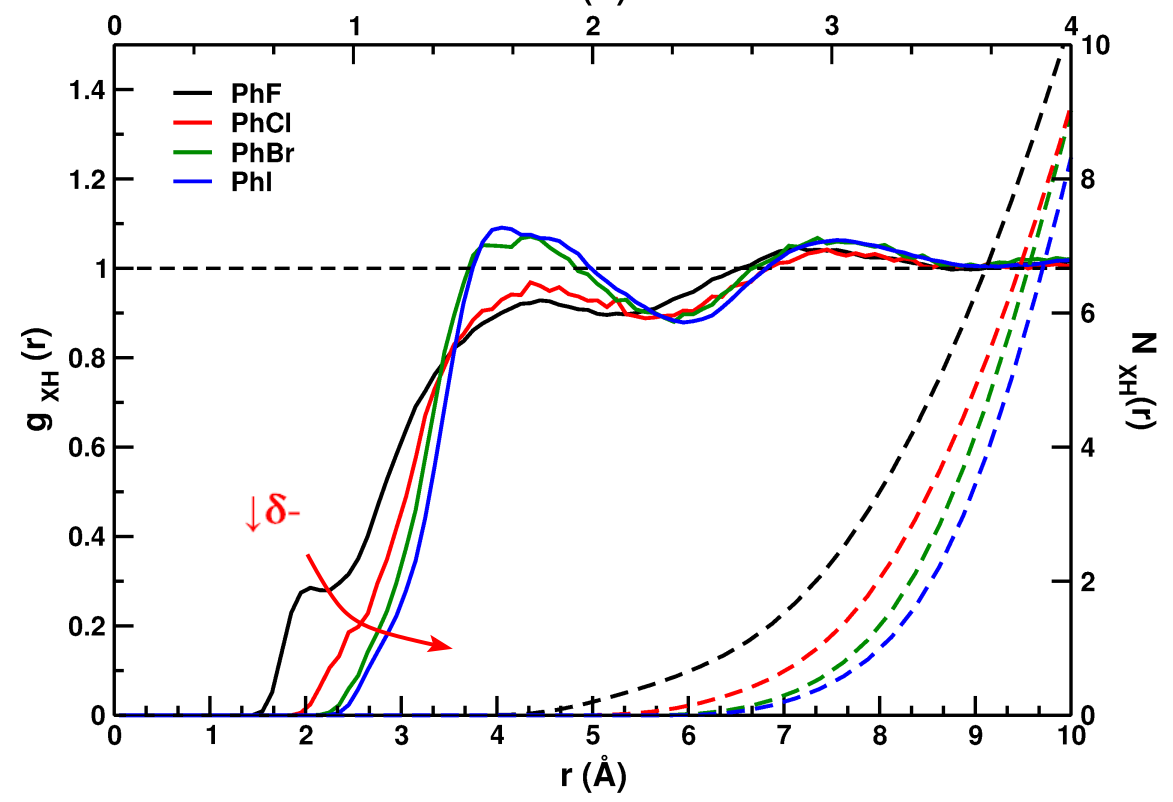

Figure 5: Superposition of the $g(r)$ from MTP simulations for $\mathrm{X}-\mathrm{O}$ (water) (a) and $\mathrm{X}-$ $\mathrm{H}$ (water) (b) for the halogens. The blue and red arrows indicate the increase (X-O(water)) and decrease $(\mathrm{X}-\mathrm{H}$ (water)) in the $g(r)$ peak, respectively, in going from $\mathrm{F}$ to $\mathrm{Cl}$ to $\mathrm{Br}$ to I. The dashed lines in the right panel are $N(r)$ for $\mathrm{X}-\mathrm{H}$ (water); the upper $x$-axis belongs to $N(r)$, and the lower $x$-axis belongs to $g(r)$. The red arrow indicates the decrease of the electron rich region $\delta^{-}$on the sides of the $\mathrm{C}-\mathrm{X}$ bond in going from $\mathrm{F}$ to $\mathrm{Cl}$ to $\mathrm{Br}$ to $\mathrm{I}$, and the blue arrow indicates the increase of the electron deficient region $\delta^{+}$along the $\mathrm{C}-\mathrm{X}$ bond from $\mathrm{F}$ to $\mathrm{Cl}$ to $\mathrm{Br}$ to $\mathrm{I}$. 
simulations for $\mathrm{C}_{\alpha}(\mathrm{Br})$ and $\mathrm{C}_{\beta}(\mathrm{Br})$. In all cases the $\mathrm{O}$ (water) and $\mathrm{H}$ (water) occupation in the first solvation shell is larger in PC simulations. The corresponding $g(r)$ s for $\mathrm{Cl}$ are similar to those of $\mathrm{Br}$ in all cases. The calculated $N(r)$ from MTP simulations for $\mathrm{Br}$ and $\mathrm{F}$ (Figure 6C) show H-bonding in the first solvation shell with a larger $N(r)$ for $\mathrm{C}_{\beta}$ than for $\mathrm{C}_{\alpha}$ in $\mathrm{PhBr}$ and a similar occupation number for $\mathrm{C}_{\beta}$ and $\mathrm{C}_{\alpha}$ in $\mathrm{PhF}$, but higher than that of PhBr. Hence, larger $N(r)$ leads to reduced $\Delta G_{\text {hyd }}$. This is consistent with the fact that fluorine is more electronegative and attracts more water molecules, thus affecting also the waters around the $\mathrm{C}_{\alpha}$ and the $\mathrm{C}_{\beta}$ carbons since these water molecules are H-bonded to one another. Moreover, the results for the MTP model are consistent with those from DFTB2 simulations (data not shown). 
A)
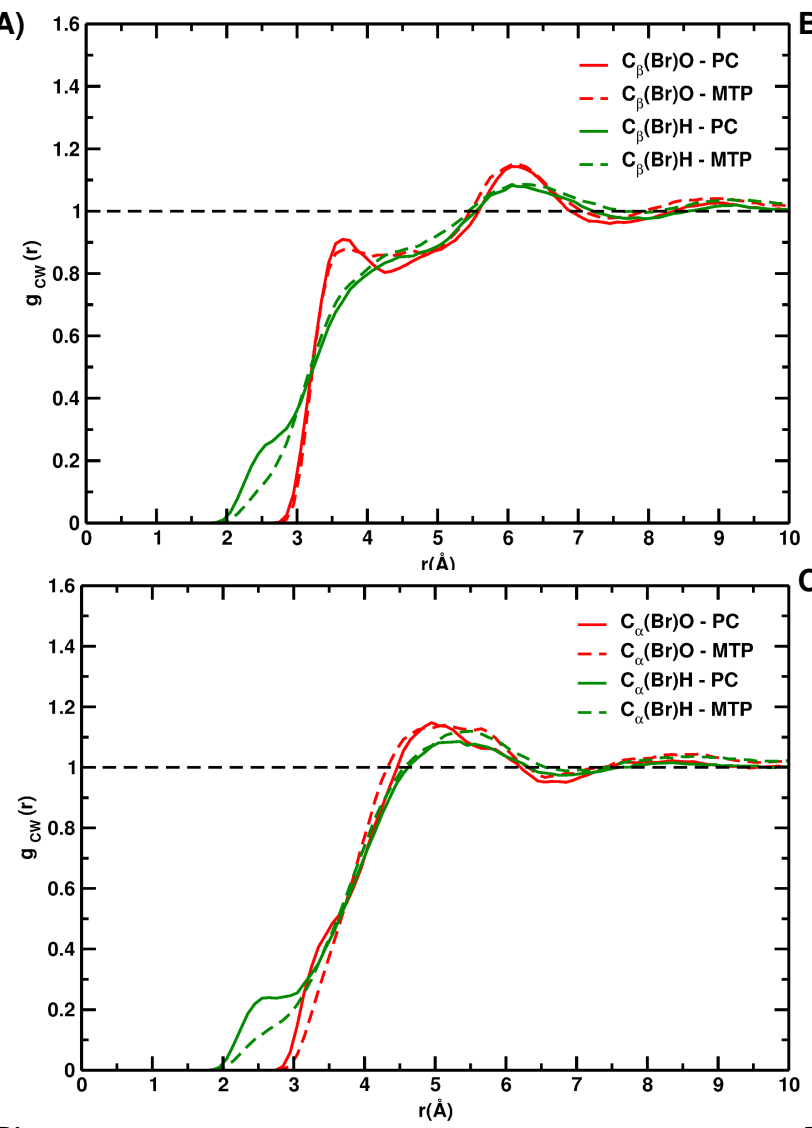

D)

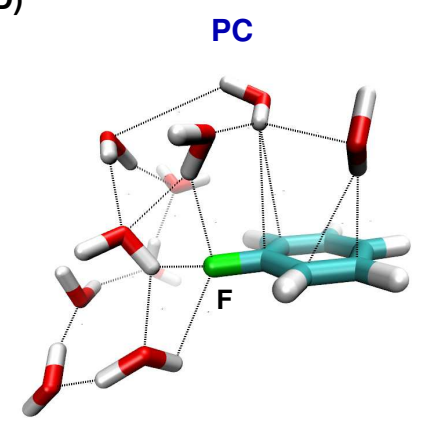

MTP

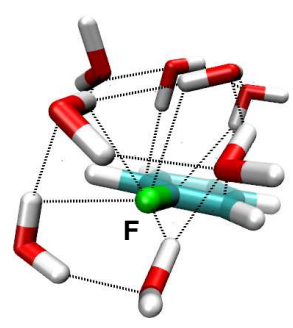

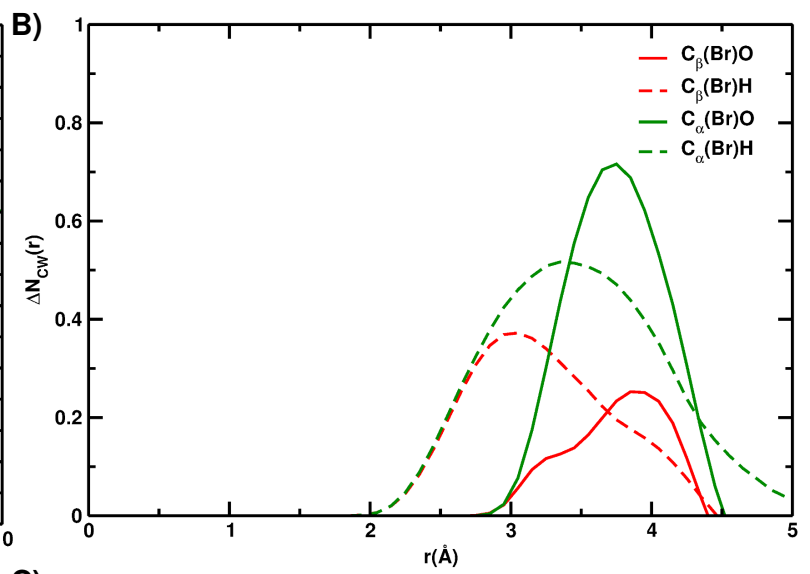

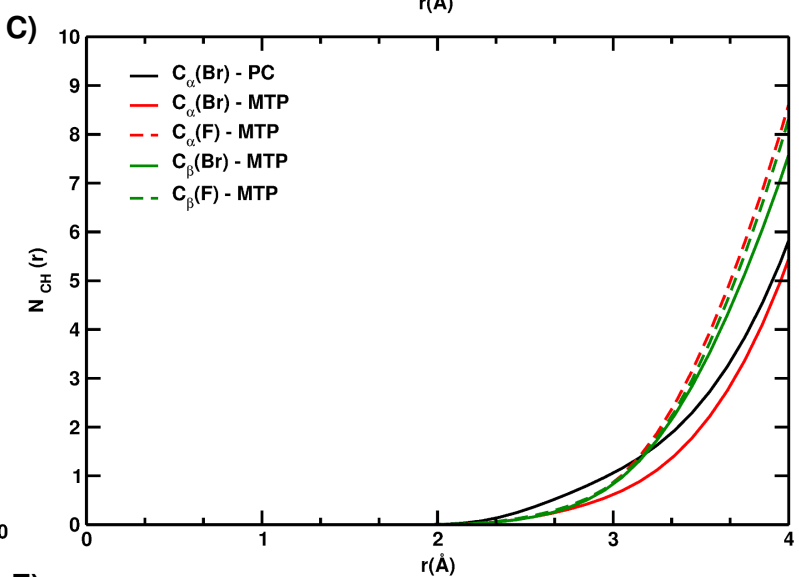

E)

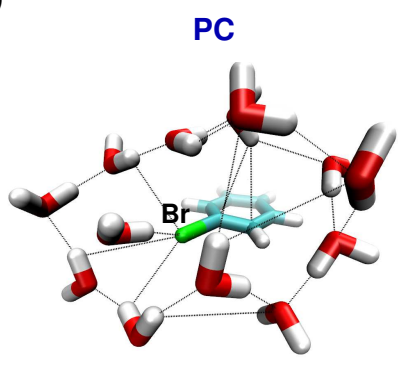

MTP

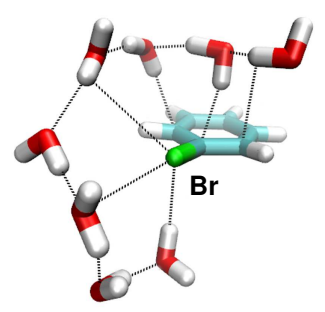

Figure 6: Radial distribution function $g(r)$ and the occupation number of hydrogen atoms $N(r)$ around the carbons adjacent to the $\mathrm{CX}$ bond $\left(\mathrm{C}_{\beta}\right)$ and the $\mathrm{CX}$ carbon $\left(\mathrm{C}_{\alpha}\right)$. Panel $\mathrm{A}: g(r)$ for $\mathrm{C}_{\beta}(\mathrm{Br})$-water $(\mathrm{O})$ and -water $(\mathrm{H})$ (upper panel) and $\mathrm{C}_{\alpha}(\mathrm{Br})$-water $(\mathrm{O})$ and water $(\mathrm{H})$ (lower panel) from PC and MTP simulations. Panel B: $\Delta N(r)$ between PC and MTP simulations for $\mathrm{C}_{\beta}(\mathrm{Br})$ and $\mathrm{C}_{\alpha}(\mathrm{Br})$ with -water $(\mathrm{O})$ and -water $(\mathrm{H})$. Panel $\mathrm{C}: N(r)$ of $\mathrm{C}_{\alpha}(\mathrm{X})$-water $(\mathrm{H})$ for PC and MTP simulations for Br and F. Panels D and E: Snapshots of the organized water network around the halogen $\mathrm{X}, \mathrm{C}_{\alpha}$ and $\mathrm{C}_{\beta}$ from the $2 \mathrm{~ns} \mathrm{PC}$ and MTP simulations for $\mathrm{F}$ and $\mathrm{Br}$, respectively.

Different orientations of water molecules around the compound and the halogen atom are present. However, the water network around $\mathrm{X}, \mathrm{C}_{\alpha}$ and $\mathrm{C}_{\beta}$ is organized and exhibits well 
defined H-bonds to these atoms and between each other (Figure 6D, E). Owing to the double nature of the sigma-hole, two types of bonds are formed: one between the $\delta^{-}$region and water $(\mathrm{H})$ on the flanks and one between the $\delta^{+}$region of the sigma-hole and water $(\mathrm{O})$ along the $\mathrm{CX}$ axis. For the $\mathrm{PC}$ model, a water $(\mathrm{H})$ will always point towards the $\mathrm{X}$ atom along the CX bond, indicative of an incipient H-bond (Figure 6D,E (PC)). This is a further reason why the PC model, lacking the $\delta^{+}$region, can not correctly describe the halogenwater interactions. As for the MTP model, water molecules are oriented such as to allow hydrogen-bonding between the (water)H and the $\delta^{-}$region and halogen-bonding between the (water)O and the $\delta^{+}$region of the sigma-hole. This is clearly observed for $\mathrm{Br}$ (Figure $6 \mathrm{E}$ ), because the magnitude of the $\delta^{+}$region is very large compared to that of $\mathrm{F}$ (Figure 6D (MTP)). Hence, the water molecules are more dispersed and allow for a certain water molecule to interact with the $\delta^{+}$region through its oxygen atoms. Within this water network, the water molecules bound to $\mathrm{C}_{\alpha}$ and $\mathrm{C}_{\beta}$ are also affected by the electrostatic model of $\mathrm{X}$, and vice-versa. Therefore, misrepresenting the electrostatics around one of these atoms will destabilize the water network. On that account, the water network organization around $\mathrm{X}, \mathrm{C}_{\alpha}$ and $\mathrm{C}_{\beta}$ provides a microscopic explanation for the difference in the calculated $\Delta G_{\mathrm{hyd}}$ between electrostatic models, and they show why by including an off-the-plane quadrupolar contribution on the carbons adjacent to the CX bond (HYB3 model) the experimental $\Delta G_{\text {hyd }}$ values can be accurately reproduced.

Finally, the influence of the size of I on the electrostatic representation of the adjacent carbons was probed. The $\Delta g(r)$ s of the different electrostatic models with respect to the MTP simulation were plotted for $\mathrm{C}_{\alpha}$ and $\mathrm{C}_{\beta}$ of $\mathrm{PhI}$ and compared to $\mathrm{PhCl}$, a smaller halogen containing phenyl, as reference (Figure 7). For PhCl, HYB1 and HYB2, lacking both MTP on $\mathrm{C}_{\beta}$, present the same large $g(r)$ deviation with respect to the MTP model, whereas HYB3, with MTPs on the CX group and $\mathrm{C}_{\beta}$, has the same behavior of MTP (Figure 7 left panel). While, for PhI, the $g(r) \mathrm{s}$ of $\mathrm{C}_{\alpha}$ and $\mathrm{C}_{\beta}$ present a similar behavior between the 3 hybrid 
models (HYB1,2 and 3), with a small deviation compared to the MTP model (Figure 7 right panel). These observations show that the large vdW radius of $\mathrm{I}$ masks $\mathrm{C}_{\alpha}$ and $\mathrm{C}_{\beta}$ 's contributions to the solvent dynamics and thus the reproduction of the anisotropy around these sites by adding a quadrupolar contribution can be ignored. This correlates and provides a valid explanation why placing off-site charges on X, as in OPLS-AAX, leads to satisfactory agreement with experiment for I and not for $\mathrm{Cl}$.
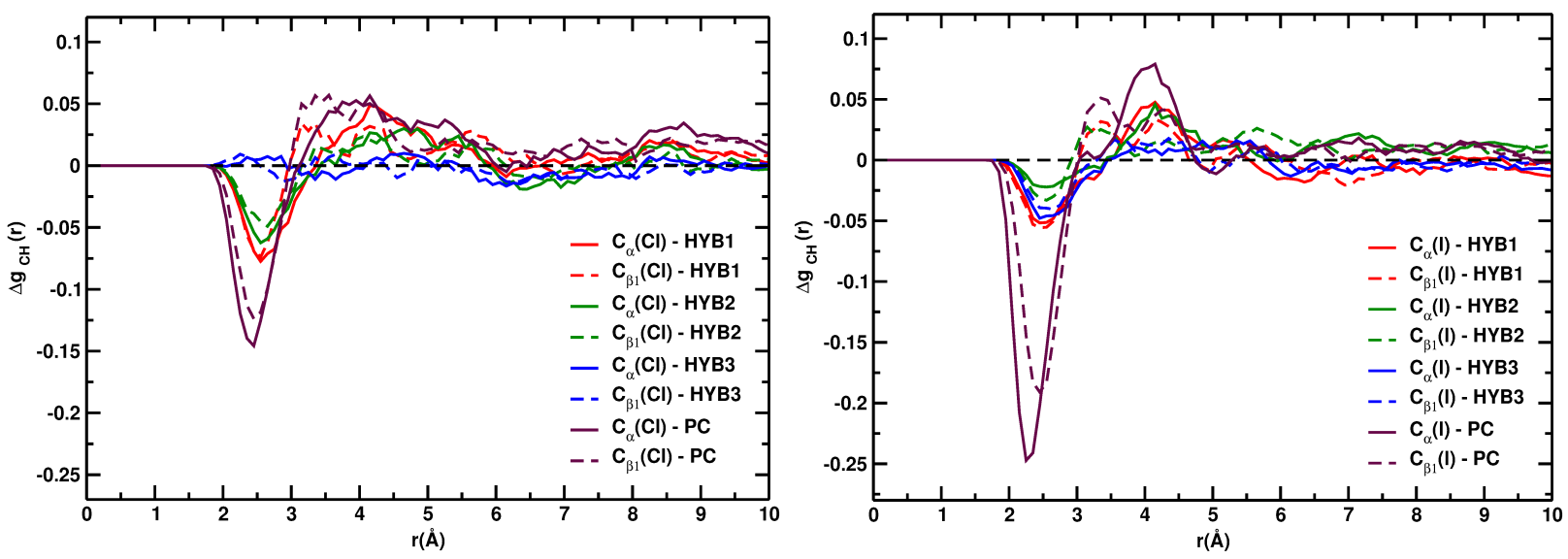

Figure 7: RDF evolution curve differences $\Delta g(r)$ with water $(\mathrm{H})$ of the different electrostatic models with respect to the MTP simulation, for the $\mathrm{C}_{\alpha}$ and the $\mathrm{C}_{\beta}$ carbons of $\mathrm{PhCl}$ (left panel) and $\mathrm{PhI}$ (right panel).

These findings highlight the delicate balance between sterics (encoded in the atoms' van der Waals parameters) and electrostatic anisotropy (order and placement of MTPs) of the interactions. As the ordering of the water molecules around a particular halogen differs for PC and MTP treatments, such a conformational contribution directly affects the thermodynamic property determined from it. This is consistent with an earlier study ${ }^{68}$ describing a simple but accurate method to decompose the free energy into its entropic and energetic components. It was shown that the large changes of the solvent structure on dissolution of the solute occur in the first and second solvation shells which contributed most to the energy, whereas the reorganization of all solvent molecules contributes to entropy changes. In yet another study, ${ }^{69}$ calculated free energies and entropies were shown to correlate with the 
change in the number of hydrogen bonds and that this increase in water-solute interaction is entropically unfavorable.

\subsection{Application of Mixed Models to Protein-Ligand Binding}

The effect of the charge distribution anisotropy on the halogen was previously investigated on the stability and affinity within a protein-ligand complex, of which Cyclin-dependent Kinase 2 (CDK2), ${ }^{30}$ Caseine Kinase 2 (CK2) ${ }^{26,32}$ and non-nucleoside inhibitors of HIV reverse transcriptase (NNRTIs) ${ }^{27}$ with polyhalogenated ligands. In the same spirit, the efficiency of the hybrid model HYB3 was then tested in protein-ligand binding. It was previously demonstrated that accurately describing the sigma-hole of the halogenated compound has a large impact on protein-ligand binding affinity. ${ }^{26}$ The study compared the binding of 4,5,6,7tetrabromobenzotriazole ${ }^{70}$ with CK2 between PC and MTP electrostatics. It was found that the ligand represented with MTP was up to $3.8 \pm 0.3 \mathrm{kcal} / \mathrm{mol}$ more stable than the ligand represented with PC. 
A)

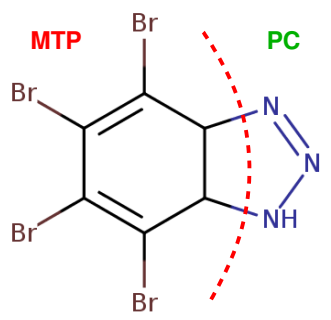

B)

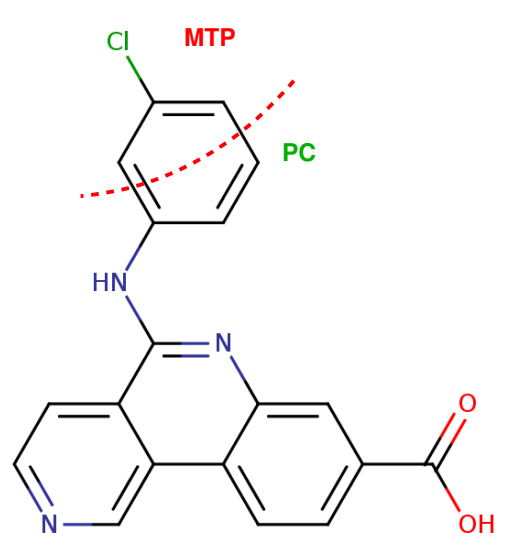

C)

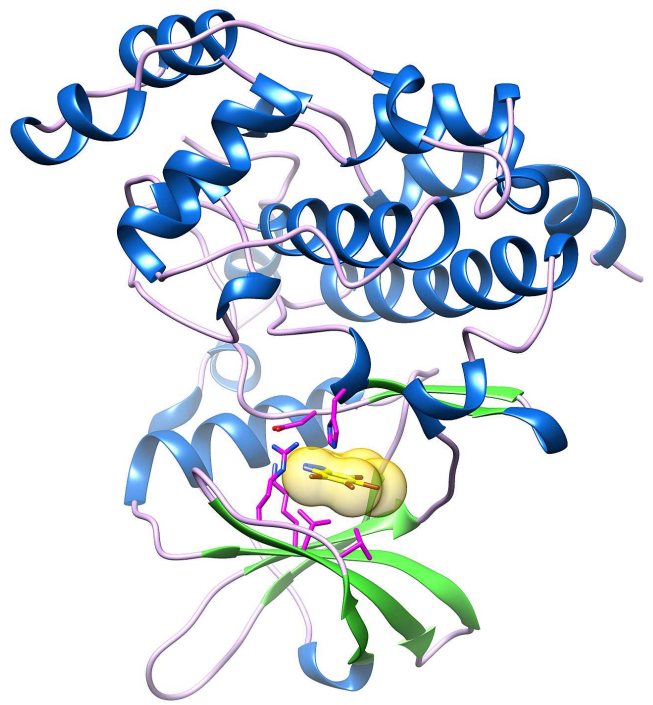

Figure 8: Casein Kinase II inhibitors TBS and 3NG. Schematic representation of the chemical structure of TBS (a) 4,5,6,7-tetrabromobenzotriazole and 3NG (b) 5-[(3chlorophenyl)amino]benzo[c][2,6]naphthyridine-8-carboxylic acid, along with the electrostatic treatment applied in the spirit of the HYB3 model. The red dashed arc separate between MTP and PC treated atoms. (c) Cartoon representation of the protein-ligand complex (taken from PDB: 1J91, chain A bound to TBS). Side chain atoms of residues involved in interactions with TBS are indicated as magenta sticks, and the ligand is englobed with a yellow transparent surface in the ligand-binding pocket.

For this, we studied the binding of two halogenated ligands 4,5,6,7-tetrabromobenzotriazole $\mathrm{TBS}^{70}$ and 5-[(3-chlorophenyl)amino]benzo[c] $[2,6]$ naphthyridine-8-carboxylic acid $3 \mathrm{NG}^{71}$ with CK2 (PDBs:1J91 ${ }^{71}$ and 3PE1, ${ }^{72}$ respectively) using HYB3 electrostatics and compared against PC and MTP treatments. This system was chosen for the complexity of the ligands and to invoke the transferability of the PC, MTP and LJ parameters previously found ${ }^{26}$ for these atom types. The ligand's PC/MTP and LJ coefficients were those parametrized for halobenzenes and pyrrole by Bereau et $a l .,{ }^{26}$ while the water, protein and chloride-counterion parameters were those from the CHARMM22-CMAP force field. ${ }^{73-75}$ Since hydrogens are unresolved in the crystal structure, the triazole hydrogen of the TBS ligand was positioned towards ARG47 instead of PHE113, to allow formation of possible H-bonds between the NH and the anionic residue ASP175. The hydration free-energies were calculated using TI in both protein and bulk water environments. For this NPT simulations were performed along 
with restraining potentials on the ligands to help converge the sampling of the free-energy calculations. ${ }^{76-78}$ Parameters of the restraining potentials were estimated from a 120 ps equilibration simulation. Indvidual TI simulations were run with $\delta \lambda=0.05$ spacings with a further 10 ps equilibration and 40 ps production runs. Three electrostatic models were generated for the ligands: a PC, an MTP and a HYB3 model. For TBS, the HYB3 model consisted in placing MTPs on the tetrabromobenzene and PCs on the triazole ring, as represented in figure $8(\mathrm{~A})$. As for $3 \mathrm{NG}$, only the chlorobenzene ring was considered, and MTPs were placed on $\mathrm{Cl}, \mathrm{C}_{\alpha}$ and both $\mathrm{C}_{\beta}$ s (see Figure $8(\mathrm{~B})$ ).

The protein-ligand free energy difference between the ligand represented with PC and with $\mathrm{MTP} / \mathrm{HYB} 3$ electrostatics $\Delta \Delta G_{\text {bind }}^{\mathrm{PC} \rightarrow \mathrm{MTP} / \mathrm{HYB} 3}=\Delta G_{\text {bind }}^{\mathrm{MTP} / \mathrm{HYB} 3}-\Delta G_{\text {bind }}^{\mathrm{PC}}$, quantifies the relative stability of PC, MTP and HYB3 simulations. For TBS, we obtain a free energy difference of $\Delta \Delta G_{\text {bind }}^{\mathrm{PC} \rightarrow \mathrm{MTP}}=-3.6 \pm 0.3 \mathrm{kcal} / \mathrm{mol}$ and $\Delta \Delta G_{\mathrm{bind}}^{\mathrm{PC} \rightarrow \mathrm{HYB} 3}=-3.2 \pm 0.3 \mathrm{kcal} / \mathrm{mol}$ for the MTP and the HYB3 model, respectively. MTP results are on par with the results previously found by Bereau et $a l .{ }^{26}$ For $3 \mathrm{NG}$, we obtain a free energy difference of $\Delta \Delta G_{\text {bind }}^{\mathrm{PC} \rightarrow \mathrm{MTP}}=-1.3 \pm 0.4$ $\mathrm{kcal} / \mathrm{mol}$ and $\Delta \Delta G_{\mathrm{bind}}^{\mathrm{PC} \rightarrow \mathrm{HYB} 3}=-1.1 \pm 0.4 \mathrm{kcal} / \mathrm{mol}$ for the MTP and the HYB3 model, respectively. In both cases, HYB3 reproduces the MTP results within statistical error. Both models show the same increased stability compared to a standard PC force field. The difference in stability matches the added hydration free energy provided by all four bromine for TBS, and the added hydration free energy provided by $\mathrm{Cl}$ for 3NG. The larger free energy difference observed for TBS emerges from the presence of four Br whereas 3NG contains only one halogen. In other words, for TBS an average difference of 0.8 to $0.9 \mathrm{kcal} / \mathrm{mol}$ between PC and MTP and HYB3 models per halogenation site is found which nicely reflects the 1.3 and $1.1 \mathrm{kcal} / \mathrm{mol}$ found for $3 \mathrm{NG}$. This analysis demonstrates the transferability of the parameters used and supports the conclusion that including MTPs on carbon atoms adjacent to a halogenated site into PC-based force fields is mandatory to improve the energetics and structural dynamics. 
The cost-efficiency of the HYB3 model over a full MTP model, was also evaluated. For this, a pure liquid simulation of a $28 \AA$ box containing $150 \mathrm{PhI}$ molecules was run for 120 ps. The computing time is considerably reduced by $44 \%$ for such a system containing 1800 atoms which is non-negligible. In protein-ligand simulations, where MTP electrostatics are applied on the ligand only the CPU time ratio between MTP and PC simulations is estimated to be $\approx 1.2$ (20\% overhead). ${ }^{26}$ When applying HYB3 electrostatics on the ligand instead of MTP, the CPU time is further reduced lowered to around 1.1 which is almost on par with the timing of PC-only simulations but at considerably improved accuracy.

\section{Conclusions}

The present work focuses on capturing the charge distribution around halogenated benzenes using empirical force fields, and to link energetics and halogen-water dynamics. Halogenation of phenyl rings not only leads to formation of a sigma-hole on the halogen but also to a pronounced reorganization of the electron density around the modification site which has, however, attracted less attention. Significant out-of-plane contributions are found on the neighboring $\beta$ carbons - an observation we make both at the electronic-structure level and identify its thermodynamic impact when immersed in water. The results rationalize previous difficulties encountered in modeling halogens with point-charge models and off-site charges: reproducing the positive lobe of the sigma-hole is not sufficient to recover the thermodynamics of a halogen in water - as found by 0.5 to $1 \mathrm{kcal} / \mathrm{mol}$ discrepancies in predicting hydration free energies. Such a difference amounts to close to 1 order in binding affinity per substitution - of critical relevance for pharmaceutically-active compounds ${ }^{9}$ or halogenated proteins. ${ }^{79}$ The quadrupolar contributions are included in the hybrid model HYB3 which yields close-to-identical hydration free energies compared with a full MTP description. How- 
ever, it should be noted that other properties, e.g. stacking interactions, may still require a full MTP description.

The quadrupolar contributions can be ignored in the case of I, where its large vdW radius masks $\mathrm{C}_{\beta}$ 's contributions to the solvent dynamics. This finding explains why placing off-site charges on X, as in OPLS-AAX, leads to satisfactory agreement with experiment for I and not for $\mathrm{Cl}$ and $\mathrm{Br}$. Halogenation is a case where quadrupolar electrostatic are mandatory on atoms two bonds away from the halogen for predictive computational work in drug design and in material sciences. We propose a new hybrid PC/MTP model for halogenated compounds that has the accuracy of MTP calculations at a lower computational cost. Beyond simulation models, we expect these conclusions to be useful in practice when rationally designing halogenated drugs.

\section{Acknowledgments}

Support by the Swiss National Science Foundation through grants 200021-117810, the NCCR MUST, and the University of Basel is gratefully acknowledged.

\section{Associated Content}

\section{Supporting Information}

Force field parametrization details. The full electron localization function ELF analysis. Radial distribution function $g(r)$ of all aromatic carbons in $\mathrm{PhCl}$ with water $\mathrm{O}$ and water $\mathrm{H}$ from PC and MTP simulations, plus the corresponding difference curves $\Delta g(r)$ from both electrostatic models; $g(r)$ for water molecules around the $\mathrm{C} \alpha$ carbon and the adjacent $\mathrm{C} \beta$ carbons taken from PC and MTP simulations, and for all halogens. This information is available free of charge via the Internet at http://pubs.acs.org. 


\section{References}

(1) Hernandes, M. Z.; Cavalcanti, S. M. T.; Moreira, D. R. M.; de Azevedo, J.; Filgueira, W.; Leite, A. C. L. Curr. Drug Targets 2010, 11, 303-314.

(2) Matter, H.; Nazar, M.; Gssregen, S.; Will, D.; Schreuder, H.; Bauer, A.; Urmann, M.; Ritter, K.; Wagner, M.; Wehner, V. Angew. Chem., Int. Ed. 2009, 48, 2911-2916.

(3) Müller, K.; Faeh, C.; Diederich, F. Science 2007, 317, 1881-1886.

(4) Metrangolo, P.; Neukirch, H.; Pilati, T.; Resnati, G. Acc. Chem. Res. 2005, 38, 386395.

(5) Metrangolo, P.; Meyer, F.; Pilati, T.; Resnati, G.; Terraneo, G. Angew. Chem., Int. Ed. 2008, 47, 6114-6127.

(6) Lommerse, J. P. M.; Stone, A. J.; Taylor, R.; Allen, F. H. J. Am. Chem. Soc. 1996, $118,3108-3116$.

(7) Auffinger, P.; Hays, F. A.; Westhof, E.; Ho, P. S. Proc. Natl. Acad. Sci. U. S. A. 2004, 101, 16789-16794.

(8) Riley, K. E.; Hobza, P. Cryst. Growth Des. 2011, 11, 4272-4278.

(9) Hardegger, L. A.; Kuhn, B.; Spinnler, B.; Anselm, L.; Ecabert, R.; Stihle, M.; Gsell, B.; Thoma, R.; Diez, J.; Benz, J.; Plancher, J.-M.; Hartmann, G.; Banner, D. W.; Haap, W.; Diederich, F. Angew. Chem., Int. Ed. 2011, 50, 314-318.

(10) Riley, K.; Murray, J.; Fanfrlík, J.; Rezáč, J.; Solá, R.; Concha, M.; Ramos, F.; Politzer, P. J. Mol. Model. 2011, 17, 3309-3318.

(11) El Hage, K.; Piquemal, J.-P.; Hobaika, Z.; Maroun, R. G.; Gresh, N. J. Comput. Chem. 2015, 36, 210-221. 
(12) Lu, Y.; Shi, T.; Wang, Y.; Yang, H.; Yan, X.; Luo, X.; Jiang, H.; Zhu, W. J. Med. Chem. 2009, 52, 2854-2862.

(13) Wilcken, R.; Zimmermann, M. O.; Lange, A.; Joerger, A. C.; Boeckler, F. M. J. Med. Chem. 2013, 56, 1363-1388.

(14) Herrera-Rodriguez, L.; Khan, F.; Robins, K.; Meyer, H.-P. Chim. Oggi 2011, 29, 31-33.

(15) Steigbigel, R. T.; Cooper, D. A.; Kumar, P. N.; Eron, J. E.; Schechter, M.; Markowitz, M.; Loutfy, M. R.; Lennox, J. L.; Gatell, J. M.; Rockstroh, J. K.; Katlama, C.; Yeni, P.; Lazzarin, A.; Clotet, B.; Zhao, J.; Chen, J.; Ryan, D. M.; Rhodes, R. R.; Killar, J. A.; Gilde, L. R.; Strohmaier, K. M.; Meibohm, A. R.; Miller, M. D.; Hazuda, D. J.; Nessly, M. L.; DiNubile, M. J.; Isaacs, R. D.; Nguyen, B.Y.; Teppler, H. N. Engl. J. Med. 2008, 359, 339-354.

(16) Shimura, K.; Kodama, E.; Sakagami, Y.; Matsuzaki, Y.; Watanabe, W.; Yamataka, K.; Watanabe, Y.; Ohata, Y.; Doi, S.; Sato, M.; Kano, M.; Ikeda, S.; Matsuoka, M. J. Virol. 2008, 82, 764-774.

(17) Fugel, W.; Oberholzer, A. E.; Gschloessl, B.; Dzikowski, R.; Pressburger, N.; Preu, L.; Pearl, L. H.; Baratte, B.; Ratin, M.; Okun, I.; Doerig, C.; Kruggel, S.; Lemcke, T.; Meijer, L.; Kunick, C. J. Med. Chem. 2013, 56, 264-275.

(18) Motel, W. C.; Healy, J. R.; Viard, E.; Pouw, B.; Martin, K. E.; Matsumoto, R. R.; Coop, A. Bioorg. Med. Chem. Lett. 2013, 23, 6920-6922.

(19) Clark, T.; Hennemann, M.; Murray, J.; Politzer, P. J. Mol. Model. 2007, 13, 291-296.

(20) Murray, J.; Lane, P.; Politzer, P. J. Mol. Model. 2009, 15, 723-729.

(21) Politzer, P.; Murray, J. S.; Clark, T. Phys. Chem. Chem. Phys. 2010, 12, 7748-7757.

(22) Politzer, P.; Murray, J. S. Chem. Phys. Chem. 2013, 14, 278-294. 
(23) Politzer, P.; Murray, J. S.; Clark, T. Phys. Chem. Chem. Phys. 2013, 15, 11178-11189.

(24) Schmid, M.; Nogueira, E. S.; Monnard, F. W.; Ward, T. R.; Meuwly, M. Chem. Sci. 2012, 3, 690-700.

(25) Hua, Q.; Nakagawa, S. H.; Jia, W.; Huang, K.; Phillips, N. B.; Hu, S.; Weiss, M. A. J. Biol. Chem. 2008, 283, 14703-14716.

(26) Bereau, T.; Kramer, C.; Meuwly, M. J. Chem. Theory Comput. 2013, 9, 5450-5459.

(27) Jorgensen, W. L.; Schyman, P. J. Chem. Theory Comput. 2012, 8, 3895-3901.

(28) Martins, S. A.; Sousa, S. F.; Ramos, M. J.; Fernandes, P. A. J. Chem. Theory Comput. 2014, 10, 3570-3577.

(29) Politzer, P.; Murray, J.; Concha, M. J. Mol. Model. 2008, 14, 659-665.

(30) Ibrahim, M. A. A. J. Comput. Chem. 2011, 32, 2564-2574.

(31) Rendine, S.; Pieraccini, S.; Forni, A.; Sironi, M. Phys. Chem. Chem. Phys. 2011, 13, $19508-19516$.

(32) Kolár̃, M.; Hobza, P. J. Chem. Theory Comput. 2012, 8, 1325-1333.

(33) Straub, J. E.; Karplus, M. Chem. Phys. 1991, 158, 221.

(34) Meuwly, M.; Becker, O.; Stote, R.; Karplus, M. Biophys. Chem. 2002, 89, 183-207.

(35) Nutt, D. R.; Meuwly, M. Biophys. J. 2003, 85, 3612-3623.

(36) Lee, M. W.; Carr, J. K.; Gllner, M.; Hamm, P.; Meuwly, M. J. Chem. Phys. 2013, 139.

(37) Cazade, P.-A.; Bereau, T.; Meuwly, M. J. Phys. Chem. B 2014, 118, 8135-8147.

(38) Cazade, P.-A.; Tran, H.; Bereau, T.; Das, A. K.; Klsi, F.; Hamm, P.; Meuwly, M. J. Chem. Phys. 2015, 142. 
(39) Gresh, N. Curr. Pharm. Des. 2006, 12, 2121-2158.

(40) Piquemal, J.-P.; Chevreau, H.; Gresh, N. J. Chem. Theory Comput. 2007, 3, 824-837.

(41) El Hage, K.; Piquemal, J.-P.; Hobaika, Z.; Maroun, R. G.; Gresh, N. J. Comput. Chem. 2013, 34, 1125-1135.

(42) Mu, X.; Wang, Q.; Wang, L.-P.; Fried, S. D.; Piquemal, J.-P.; Dalby, K. N.; Ren, P. J. Phys. Chem. B 2014, 118, 6456-6465.

(43) Du, L.; Gao, J.; Bi, F.; Wang, L.; Liu, C. J. Comput. Chem. 2013, 34, 2032-2040.

(44) Jakobsen, S.; Jensen, F. J. Chem. Theory Comput. 2014, 10, 5493-5504.

(45) Brooks, B. R.; Brooks, C. L., III; Mackerell, A. D., Jr.; Nilsson, L.; Petrella, R. J.; Roux, B.; Won, Y.; Archontis, G.; Bartels, C.; Boresch, S.; Caflisch, A.; Caves, L.; Cui, Q.; Dinner, A. R.; Feig, M.; Fischer, S.; Gao, J.; Hodoscek, M.; Im, W.; Kuczera, K.; Lazaridis, T.; Ma, J.; Ovchinnikov, V.; Paci, E.; Pastor, R. W.; Post, C. B.; Pu, J. Z.; Schaefer, M.; Tidor, B.; Venable, R. M.; Woodcock, H. L.; Wu, X.; Yang, W.; York, D. M.; Karplus, M. J. Comput. Chem. 2009, 30, 1545-1614.

(46) Jorgensen, W. L.; Tirado-Rives, J. J. Am. Chem. Soc. 1988, 110, 1657-1666.

(47) Cornell, W. D.; Cieplak, P.; Bayly, C. I.; Kollmann, P. A. J. Am. Chem. Soc. 1993, $115,9620-9631$.

(48) Cui, Q.; Elstner, M.; Kaxiras, E.; Frauenheim, T.; Karplus, M. J. Phys. Chem. B 2001, $105,569-585$.

(49) Kubař, T.; Bodrog, Z.; Gaus, M.; Köhler, C.; Aradi, B.; Frauenheim, T.; Elstner, M. J. Chem. Theory Comput. 2013, 9, 2939-2949.

(50) Jorgensen, W. L.; Chandrasekhar, J.; Madura, J. D.; Impey, R. W.; Klein, M. L. J. Chem. Phys. 1983, 79, 926-935. 
(51) van Gunsteren, W.; Berendsen, H. Mol. Phys. 1977, 34, 1311-1327.

(52) Zacharias, M.; Straatsma, T.; McCammon, J. J. Chem. Phys. 1994, 100, 9025-9031.

(53) Boresch, S. Mol. Sim. 2002, 28, 13-37.

(54) Boresch, S.; Karplus, M. J. Phys. Chem. A 1999, 103, 103-118.

(55) Frisch, M. J.; Trucks, G. W.; Schlegel, H. B.; Scuseria, G. E.; Robb, M. A.; Cheeseman, J. R.; Scalmani, G.; Barone, V.; Mennucci, B.; Petersson, G. A.; Nakatsuji, H.; Caricato, M.; Li, X.; Hratchian, H. P.; Izmaylov, A. F.; Bloino, J.; Zheng, G.; Sonnenberg, J. L.; Hada, M.; Ehara, M.; Toyota, K.; Fukuda, R.; Hasegawa, J.; Ishida, M.; Nakajima, T.; Honda, Y.; Kitao, O.; Nakai, H.; Vreven, T.; Montgomery, J. A., Jr.; Peralta, J. E.; Ogliaro, F.; Bearpark, M.; Heyd, J. J.; Brothers, E.; Kudin, K. N.; Staroverov, V. N.; Kobayashi, R.; Normand, J.; Raghavachari, K.; Rendell, A.; Burant, J. C.; Iyengar, S. S.; Tomasi, J.; Cossi, M.; Rega, N.; Millam, J. M.; Klene, M.; Knox, J. E.; Cross, J. B.; Bakken, V.; Adamo, C.; Jaramillo, J.; Gomperts, R.; Stratmann, R. E.; Yazyev, O.; Austin, A. J.; Cammi, R.; Pomelli, C.; Ochterski, J. W.; Martin, R. L.; Morokuma, K.; Zakrzewski, V. G.; Voth, G. A.; Salvador, P.; Dannenberg, J. J.; Dapprich, S.; Daniels, A. D.; Farkas, .; Foresman, J. B.; Ortiz, J. V.; Cioslowski, J.; Fox, D. J. Gaussian09 Revision D.01. Gaussian Inc. Wallingford CT 2009.

(56) Grimme, S. J. Comput. Chem. 2006, 27, 1787-1799.

(57) Dunning, T. H. J. Chem. Phys. 1989, 90, 1007-1023.

(58) Feller, D. J. Comput. Chem. 1996, 17, 1571-1586.

(59) Peterson, K. A.; Shepler, B. C.; Figgen, D.; Stoll, H. J. Phys. Chem. A 2006, 110, $13877-13883$.

(60) Becke, A.; Edgecombe, K. J. Chem. Phys. 1990, 92, 5397-5403. 
(61) Silvi, B.; Savin, A. Nature 1994, 371, 683-686.

(62) Noury, S.; Krokidis, X.; Fuster, F.; Silvi, B. Comput. Chem. (Oxford, U. K.) 1999, 23, $597-604$.

(63) Dennington, R.; Keith, T.; Millam, J. GaussView Version 5. Semichem Inc. Shawnee Mission KS 2009.

(64) Mobley, D. L. UC Irvine: Department of Pharmaceutical Sciences, UCI. California 2013.

(65) Kubillus, M.; Kubař, T.; Gaus, M.; Řezáč, J.; Elstner, M. J. Chem. Theory Comput. 2015, 11, 332-342.

(66) Zhou, P.; Lv, J.; Zou, J.; Tian, F.; Shang, Z. J. Struct. Biol 2010, 169, 172 - 182.

(67) El Hage, K.; Piquemal, J.-P.; Hobaika, Z.; Maroun, R. G.; Gresh, N. Chem. Phys. Lett. 2015, 637, $51-57$.

(68) Wan, S.; Stote, R. H.; Karplus, M. J. Chem. Phys. 2004, 121, 9539-9548.

(69) Olano, L. R.; Rick, S. W. J. Am. Chem. Soc. 2004, 126, 7991-8000.

(70) Sarno, S.; Reddy, H.; Meggio, F.; Ruzzene, M.; Davies, S. P.; Donella-Deana, A.; Shugar, D.; Pinna, L. A. FEBS Lett. 2001, 496, $44-48$.

(71) Battistutta, R.; De Moliner, E.; Sarno, S.; Zanotti, G.; Pinna, L. A. Protein Sci. 2001, 10, 2200-2206.

(72) Battistutta, R.; Cozza, G.; Pierre, F.; Papinutto, E.; Lolli, G.; Sarno, S.; OBrien, S. E.; Siddiqui-Jain, A.; Haddach, M.; Anderes, K.; Ryckman, D. M.; Meggio, F.; Pinna, L. A. Biochemistry 2011, 50, 8478-8488.

(73) MacKerell, Jr., A. D.; Bashford, D.; Bellott, M.; Dunbrack, Jr., R. L.; Evanseck, J. D.; Field, M. J.; Fischer, S.; Gao, J.; Guo, H.; Ha, S.; Joseph-McCarthy, D.; Kuchnir, L.; 
Kuczera, K.; Lau, F. T. K.; Mattos, C.; Michnick, S.; Ngo, T.; Nguyen, D. T.; Prodhom, B.; Reiher, III, W. E.; Roux, B.; Schlenkrich, M.; Smith, J. C.; Stote, R.; Straub, J. E.; Watanabe, M.; Wiorkiewicz-Kuczera, J.; Yin, D.; Karplus, M. J. Phys. Chem. B 1998, 102, 3586.

(74) MacKerell Jr., A. D.; Feig, M.; Brooks, C. L. J. Comput. Chem. 2004, 25, 1400-1415.

(75) MacKerell Jr., A. D.; Feig, M.; Brooks, C. L. J. Am. Chem. Soc. 2004, 126, 698-699.

(76) Boresch, S.; Tettinger, F.; Leitgeb, M.; Karplus, M. J. Phys. Chem. B 2003, 107, $9535-9551$.

(77) Mobley, D. L.; Chodera, J. D.; Dill, K. A. J. Chem. Phys. 2006, 125.

(78) Deng, Y.; Roux, B. J. Phys. Chem. B 2009, 113, 2234-2246.

(79) Pandyarajan, V.; Phillips, N. B.; Cox, G. P.; Yang, Y.; Whittaker, J.; Ismail-Beigi, F.; Weiss, M. A. J. Biol. Chem. 2014, 289, 23367-23381. 


\section{Graphical TOC Entry}

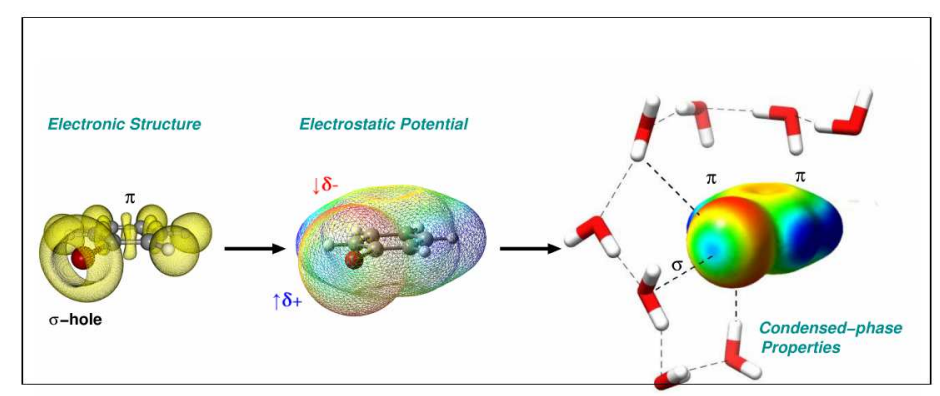

16

17

18

19

20

21

22

23

24

25

26

27

28

29

30

31

32

33

34

35

36

37

38

39

40

41

42

43

44

45

46

47

48

49

50

51

52

53

54

55

56

57

58

59

60 